\title{
La conciliación obligatoria dirigida a entidades públicas como requisito para acceder a la segunda instancia judicial ${ }^{*}$
}

\author{
Mario Cesar Tejada González ${ }^{\text {- Lizeth Vargas Sánchez }}{ }^{\mathrm{b}}$
}

\begin{abstract}
Resumen: En el presente artículo se presenta un pormenorizado recuento histórico sobre el marco legal de la implementación de la conciliación como mecanismo alternativo de solución de conflictos en Colombia (desde 1921), así como un análisis doctrinal sobre el tema. De manera específica se presentan los resultados de la investigación realizada en la jurisdicción contenciosa administrativa del departamento del Huila (Colombia), en la cual se analizan la pertinencia y la efectividad de la audiencia de conciliación obligatoria que fue impuesta como requisito para admitir los recursos de apelación contra sentencias condenatorias del Estado colombiano. Dicha medida obligatoria fue consagrada en el artículo 70 de la Ley 1395 de 2010, por la cual se modificó en su momento el Código Contencioso Administrativo de 1984 y, posteriormente, se incorpora al nuevo Código de Procedimiento Administrativo y de lo Contencioso Administrativo, expedido en el 2011 y vigente hasta la fecha.
\end{abstract}

Palabras clave: conciliación en Colombia; audiencia de conciliación; conciliación judicial; recurso de apelación sentencias; condena estatal

Fecha de recepción: 9 de noviembre de 2018 Fecha de evaluación: 25 de noviembre de 2019 Fecha de aprobación: 28 de noviembre de 2019

Cómo citar: Tejada González, M. C., \& Vargas Sánchez, L. (2020). La conciliación obligatoria para entidades públicas como requisito para acceder a la segunda instancia judicial. Prolegómenos, 23(45). https://doi.org/10.18359/prole.3755

* El presente artículo constituye el resultado de la investigación denominada "La conciliación procesal obligatoria como mecanismo de descongestión judicial en la jurisdicción contenciosa administrativa del Huila", realizada por la Universidad Surcolombiana, institución acreditada de alta calidad, a través del semillero de investigación Ratio Iuris adscrito al Grupo de Investigación Conciencia Jurídica, integrado por los estudiantes auxiliares de investigación Danna Briyith Díaz Rondón y Andrés Felipe Vela Silva.

Artículo de investigación.

a Docente de planta de tiempo completo del programa de Derecho de la Universidad Surcolombiana, Especialista y Magíster en Derecho Administrativo. Correo electrónico: mario.tejada@usco.edu.co

b Docente catedrática del programa de Derecho de la Universidad Surcolombiana, Especialista en Derecho Administrativo. Correo electrónico: lizeth.vargas@usco.edu.co 


\title{
Compulsory Conciliation Addressed to Public Entities as a Requirement to Access the Court of Appeals
}

\begin{abstract}
This paper provides a detailed historical account of the legal framework for the implementation of conciliation as an alternative conflict resolution mechanism in Colombia (since 1921), as well as a doctrinal analysis on the subject. Specifically, it presents the results of the research conducted into the contentious administrative jurisdiction of the Huila Department (Colombia). The relevance and effectiveness of the compulsory conciliation hearing that was imposed as a requirement to admit appeals against judgments of the Colombian state are discussed. This measure was included in Article 70 of Law 1395/2010, whereby the 1984 Contentious Administrative Code was amended and the new Code of Administrative and Contentious Administrative Procedure, issued in 2011 and still in force, was subsequently incorporated.

Keywords: Conciliation in Colombia; conciliation hearing; judicial conciliation; appeal of judgments; state sentence.
\end{abstract}

\section{A conciliação obrigatória dirigida a entidades públicas como requisito para ter acesso à segunda instância judicial}

\footnotetext{
Resumo: Neste artigo, é apresentada uma detalhada recontagem histórica sobre o referencial legal da implantação da conciliação como mecanismo alternativo de solução de conflitos na Colômbia (desde 1921), bem como uma análise da doutrina sobre a temática. De maneira específica, são apresentados os resultados da pesquisa realizada na jurisdição contenciosa administrativa de Huila, Colômbia, na qual são analisadas a pertinência e a efetividade da audiência de conciliação obrigatória que foi imposta como requisito para admitir os recursos de apelação contra sentenças condenatórias do Estado colombiano. Essa medida obrigatória foi consagrada no artigo 70 da Lei 1.395 de 2010, pelo qual foi modificado, em seu momento, o Código de Procedimento Administrativo e do Contencioso Administrativo, expedido em 2011 e válido até hoje.

Palavras-chave: conciliação na Colômbia; audiência de conciliação; conciliação judicial; recurso de apelação de sentenças; condenação estatal.
} 


\section{Introducción}

Como consecuencia de la crítica situación de congestión de los despachos judiciales en Colombia, se hizo necesaria la búsqueda de medidas que evitaran la presentación de procesos ante los despachos judiciales, así como de un procedimiento rápido y eficaz que agilizara el trámite del gran cúmulo de procesos inactivos que reposan en los anaqueles de los juzgados.

En atención a esto, la Corte Constitucional, en la Sentencia C-902 de 2008, al referirse a la conciliación expresó:

ha sido un mecanismo alternativo para la resolución de conflictos, por cuyo intermedio las partes, con la ayuda de un tercero neutral, calificado y autorizado para ello, resuelven directamente un asunto en el que se presenta desacuerdo y que es susceptible de ser conciliable.

Es decir, tal y como lo menciona, es un mecanismo mediante el cual se busca que una controversia o conflicto en desarrollo se solucione de forma eficaz y sin necesidad de acudir a una instancia judicial.

Conforme al tema objeto de análisis y a la problemática abordada en el marco del estudio realizado, se ha considerado que los mecanismos alternativos de solución de conflictos, entre los cuales se encuentra la denominada conciliación, han surgido no solo como respuesta a un aparato judicial congestionado a causa de la gran cantidad de asuntos por resolver, sino porque estos proporcionan un acuerdo que es elaborado por las partes $y$ en el cual se han tenido en cuenta previamente sus intereses. Es decir, les brindan la oportunidad a las partes mediante argumentos soportados con pruebas, de modo que puedan realizar propuestas de arreglo de acuerdo con lo que consideren tienen derecho dentro del proceso.

Fue así que, en atención a tal situación, en procura de brindar nuevas soluciones a la realidad jurídica del país y dada la urgente necesidad de adecuar el Código Contencioso Administrativo (Decreto 01 de 1984) a la nueva Constitución de 1991, se expidió el artículo 70 de la Ley 1395 de 2010, por la cual se adoptaron medidas en materia de descongestión judicial. Además, luego se sancionó la Ley 1437 de 2011, por la cual se expidió el Código de Procedimiento Administrativo y de lo Contencioso Administrativo, lo que supuso varias medidas de descongestión y de celeridad en el procedimiento contencioso. Una de ellas se encuentra en el inciso $4^{\circ}$ del artículo 192, el cual establece que ante los fallos que impongan condena a una entidad pública y se apelen de manera previa a la admisión del recurso, deberá citarse a una audiencia de conciliación obligatoria.

En razón a lo anterior fue necesaria la realización de una investigación en la que se lograra realizar un análisis de esta medida de descongestión, en la jurisdicción contenciosa administrativa del Huila, a fin de establecer si resultaba efectiva, en el entendido de utilizarse o no la conciliación para la terminación de los litigios. Asimismo, se realiza un análisis sobre su pertinencia, bajo la premisa de sus resultados económicos en beneficio del erario público del Estado colombiano.

El objetivo general de la investigación fue determinar la pertinencia, como medida de descongestión judicial, de la audiencia de conciliación obligatoria, de la que tratan los artículos 70 de la Ley 1395 de 2010 y el inciso $4^{\circ}$ del artículo 192 de la Ley 1437 de 2011 en la jurisdicción contenciosa administrativa del Huila, en el periodo 2011-2015. Dicho objetivo fue alcanzado a través de cuatro objetivos específicos que, desarrollados uno a uno, permitieron identificar los diferentes procesos en los que se había proferidos fallos condenatorios al Estado, así como establecer los diferentes factores que influyeron en el desarrollo de la audiencia de conciliación. Finalmente, lo anterior permitió establecer el impacto en materia de descongestión judicial que conlleva la practica de esta audiencia.

Fue así como se analizaron los diversos factores determinantes del fracaso de la audiencia de conciliación obligatoria, al ser el principal motivo la falta de ánimo conciliatorio de las entidades públicas al momento de la audiencia. Todos estos factores que respondían al fracaso de esta audiencia se extrajeron de las actas de audiencias de conciliación levantadas por cada uno de los despachos administrativos, lo que permitió presentar una interpretación amplia de la problemática objeto de examen. 
El presente artículo constituye el resultado de la investigación "La conciliación procesal obligatoria como mecanismo de descongestión judicial en la jurisdicción contenciosa administrativa del Huila", realizada por la Universidad Surcolombiana por medio del semillero de investigación Ratio Iuris, adscrito al Grupo de Investigación Conciencia Jurídica, integrado por los estudiantes auxiliares de investigación Danna Briyith Díaz Rondón y Andrés Felipe Vela Silva. Se desarrolló bajo la tutoría del docente Mario Cesar Tejada González. El proyecto se ejecutó de forma continua y bajo un arduo trabajo en equipo, con lo cual se logró la consolidación de un artículo con fundamentos y resultados precisos.

En conformidad con lo señalado, se ponen a disposición de la comunidad académica los resultados presentados en este trabajo. Cuentan estos con un alto grado de confiabilidad, ya que para la investigación se analizó y estudió de forma exhaustiva una muestra del $10 \%$ de la totalidad de los procesos contenciosos administrativos de los juzgados administrativos de Neiva y el Tribunal Administrativo del Huila durante el periodo 2011-2015. Esta muestra incluyó la totalidad de las sentencias condenatorias conciliadas. Es preciso detallar que, mediante dicha investigación, se buscó la obtención de una muestra relevante que detallara de forma precisa la situación que en la actualidad refleja la jurisdicción contenciosa administrativa del Huila en temas de conciliación y congestión judicial. Lo anterior, con el fin de precisar si ha sido o no efectiva la conciliación en materia de descongestión judicial.

\section{A. Desarrollo del tema}

\section{Referente global de la conciliación}

A lo largo de la historia siempre han existido referentes que demuestran la capacidad del hombre de despojarse de sus posiciones radicales con el propósito de llegar a un acuerdo que genere un beneficio mutuo en pro de una convivencia en armonía.

De esta forma, mediante investigaciones y proyectos llevados a cabo por tratadistas de diversas partes del mundo, se ha evidenciado que la conciliación ha sido un mecanismo de resolución de conflictos que data de muchos años atrás. Así, en diferentes países, continentes e incluso imperios se ha visto enmarcada la conciliación como una figura cuyo objetivo es el acuerdo entre sus asociados, la resolución de conflictos de convivencia y jurídicos que, al final, buscan garantizar la paz y la armonía en la comunidad.

De acuerdo con lo anterior, se hace pertinente destacar las diferentes formas de conciliación llevadas a cabo por diversas naciones a lo largo de la historia.

Como uno de los principales referentes se encuentra China, donde, "según Confucio, los conflictos se solucionaban con la persuasión moral y el acuerdo, y no bajo coacción" (Osorio, 2002, p. 11). Es decir, la violencia y la fuerza no se buscaban en el momento de resolver una controversia, sino que, por el contrario, lo esencial era la búsqueda de un acuerdo entre las partes en conflicto. Todavía hoy, en el siglo xxI, podemos observar que existen comités populares en dicha región cuyo objetivo es ejercer la conciliación y buscar de esta manera la resolución de sus conflictos de forma pacífica.

Asimismo, destacamos el continente africano, donde las controversias se solucionaban de manera informal, a manera de reunión o junta de vecinos. En estas las personas líderes y cabezas de familia dialogaban de forma directa con las partes a fin de buscar una solución a su controversia, es decir, en esta región también se evidenció la conciliación como mecanismo directo a la hora de resolver un conflicto.

Actualmente, la conciliación ha tenido un gran fortalecimiento en los países latinoamericanos, los cuales han tomado especial conciencia en fortalecer los mecanismos alternativos de resolución de conflictos mediante el desarrollo de normatividad en cada uno de sus ordenamientos jurídicos. De esta forma, en países como México y Colombia, entre otros, la conciliación, más que buscar la resolución de una controversia, busca también la descongestión de los diferentes despachos judiciales.

Mario Cesar Tejada González - Lizeth Vargas Sánchez 


\section{Marco legal de la conciliación en Colombia}

En Colombia, la conciliación como mecanismo alternativo de solución de controversias existía antes de la Constitución de 1991, y para el efecto ya operaban centros de conciliación (p. ej., en las universidades) que permitían a los particulares ejercer estas funciones. Es por esto que en este estudio nos enfocaremos en presentar un recorrido a través de las diferentes leyes que se encuentran en nuestro ordenamiento jurídico a lo largo de toda la historia republicana. Estas son:

- Ley 13 de 1825. Fue la norma que abrió el camino a la conciliación en Colombia, pues, precisamente, mediante dicha ley la figura de la conciliación toma auge dentro de nuestro ordenamiento jurídico. Esto en razón a que especificaba cómo "ningún proceso se adelantaría sin intentar la conciliación ante los alcaldes municipales o parroquiales". Así las cosas, desde el siglo xix la conciliación se convertía en un requisito procesal para que un asunto pudiese llegar a una instancia judicial, o, aún más importante, para que continuara con su conocimiento.

- Ley 120 de 1920. Es la precursora de la conciliación en materia laboral, dado que impuso este mecanismo en materia de conflictos colectivos y expuso la posibilidad de conciliación prejudicial.

- Ley 14 de mayo de 1934. Mediante esta norma se estableció lo siguiente:

antes de intentarse un juicio entre las partes capaces de transigir y sobre objetos que puedan ser materia de transacción en negocios contenciosos civiles, o por injurias y en casos de divorcio, podrá intentarse el medio de conciliación, ante uno de los jueces de paz.

Así, se invitaba a las partes a que conciliaran antes de iniciar algún conflicto, con lo cual se exigía que estas fueran personas capaces y que se tratará de unos conflictos especiales.

- Decreto 2158 de 1948. Incorpora todo un capítulo de la conciliación como mecanismo para solucionar controversias en lo que se refiere a conflictos de carácter laboral individual.
Con la llegada de la Constitución de 1991, a lo que se suma la gran congestión judicial, se robusteció el mecanismo mediante su referencia en el texto constitucional y su prolija regulación en normas de distintos niveles. De esta manera, es importante realizar un breve recuento de lo que ha sido la conciliación en nuestro ordenamiento jurídico colombiano después de la llegada de dicha Carta política. En este sentido, se destaca cómo el auge de este mecanismo alternativo de resolución de conflictos ha permitido la resolución de estos no solo por intermediación del Estado, el cual ejerce el monopolio de la justicia, sino por particulares que ejercen transitoriamente funciones judiciales, tal y como lo afirma el artículo 116 de la Constitución Política de Colombia de 1991:

los particulares pueden ser investidos transitoriamente de la función de administrar justicia en la condición de jurados en las causas criminales, conciliadores o en la de árbitros habilitados por las partes para proferir fallos en derecho o en equidad, en los términos que determine la ley [cursivas añadidas].

Tenemos entonces que el nuevo esquema constitucional colombiano, adoptado en 1991, incorporó de manera expresa la posibilidad de revestir a los particulares de la capacidad de intervenir como terceros a fin de solucionar conflictos y evitar controversias judiciales.

Es el caso de los árbitros, los conciliadores y los terceros por medio de los cuales los sujetos en controversia pueden acudir en busca de una solución alternativa de los conflictos y resolverlos así de forma directa, de manera que se evite llevarlos a una instancia judicial.

- Ley 23 de 1991. Desarrollada por el Decreto 800 de 1991, es fundamental en lo que a conciliación se refiere, pues estableció procedimientos para la descongestión de despachos judiciales. En lo que respecta a la conciliación en materia del trabajo, la Ley 23 de 1991 consagró la obligación de "acudir ante las Autoridades Administrativas del Trabajo con el fin de intentar un arreglo conciliatorio, como requisito de procedibilidad para ejercer acciones ordinarias ante la Jurisdicción Laboral". En igual sentido, enuncia los asuntos objeto de conciliación antes de iniciarse la 
controversia judicial en materia de familia, sobre la que menciona asuntos tales como la fijación de la cuota alimentaria o la liquidación de sociedades conyugales, entre otros. En cuanto al tema de la conciliación en materia de lo contencioso administrativo, la Ley 23 de 1991, en su artículo 59, proporcionó la posibilidad de conciliar total o parcialmente, en las etapas prejudicial o judicial, a las personas jurídicas de derecho público y a través de sus representantes legales, sobre conflictos de carácter particular y contenido patrimonial ante la jurisdicción de lo contencioso administrativo.

- Decreto Constitucional 2651 de 1991. Expedido en uso de las facultades que la Asamblea Nacional Constituyente, le otorgó al entonces presidente de la República, César Gaviria Trujillo, normas transitorias para la descongestión de despachos judiciales. Fijó así los parámetros y las etapas por las que podía adelantarse la conciliación y, lo más importante, se habla de nuevo de los particulares como árbitros o conciliadores que quedan investidos transitoriamente de la función de administrar justicia. Esto con el objeto de lograr un arreglo directo de un conflicto, por el que las partes satisfagan su interés de justicia.

- Ley 270 de 1996. Expedida bajo los preceptos de la ley estatutaria, desarrolla todo lo relacionado con la administración de justicia. Establece así que la ley ordinaria podría determinar mecanismos alternativos de solución de controversias y que, cuando fueran los particulares los encargados de adelantar dichos mecanismos, se podría fijar legalmente el monto de los honorarios.

- Ley 446 de 1998. Recopiló las normativas del Decreto 2651 de 1991 y derogó algunas disposiciones de la Ley 23 de 1991. Trata en concreto temas como, por ejemplo, los centros de conciliación y su definición. Adicionalmente, se extendió a temas muy diversos tales como los asuntos conciliables, los efectos de la conciliación, así como aspectos del proceso arbitral y de las funciones jurisdiccionales de las superintendencias.

- Decreto Ley 1818 de 1998. Expedido en uso de las facultades legislativas otorgadas por la Ley 446 de 1998, constituyó el estatuto de los mecanismos alternativos de solución de conflictos. En él se menciona la conciliación tanto judicial como extrajudicial, y se establece que pueden ser objeto de conciliación todos los asuntos susceptibles de transacción, desistimiento o conciliación.

- Ley 640 de 2001. Esta ley constituye la base principal de regulación de la institución jurídica de la conciliación en Colombia. Derogó artículos de la Ley 446 de 1998 y de la Ley 23 de 1991. Menciona temas relevantes como lo son las clases de conciliación existentes; las calidades, facultades y obligaciones del conciliador como tercero neutral y calificado para llevar a cabo un arreglo directo entre las partes; los principios que rigen un acuerdo conciliatorio; las clases de conciliación; cuándo estamos frente a un conciliador; quiénes están autorizados para realizar un acuerdo conciliatorio y, específicamente, las diferentes áreas del derecho en las cuales es viable realizar una audiencia de conciliación.

De acuerdo con esta norma existen dos clases de conciliación. Como primera medida, encontramos la conciliación extrajudicial, la cual se realiza antes o por fuera de un proceso judicial. Allí las partes resuelven de manera pacífica los conflictos sin necesidad de llegar hasta un juicio, de manera que puede tener el carácter de obligatoria; se denomina también "requisito de procedibilidad". En segundo término, se encuentra la conciliación judicial. Esta se lleva a cabo en el marco de un proceso judicial, en el cual la conciliación está en cabeza del juez, quien en una etapa procesal tiene la potestad de tratar de dialogar de forma directa con las partes; se busca de esta forma la resolución del conflicto y evitar que tenga continuidad. Para esto, el juez cita a las partes a una audiencia denominada "audiencia de conciliación”, en la cual estas y el Ministerio Público tomarán lugar en la sala de audiencia, en la hora y la fecha asignada por el juez. Deben llevar consigo una propuesta de conciliación que, en caso de ser aceptada por las partes, deberá ser aprobada por el juez, quien verificará que se haya hecho de forma legal, respetando los derechos de cada parte en cuestión. 


\section{Conciliación en materia contenciosa administrativa}

Ahora bien, en razón a que el tema objeto de estudio de este artículo se encuentra directamente relacionado con la conciliación en materia contenciosa administrativa, resulta pertinente exponer un breve recuento de la normativa que rige esta clase de conciliación.

La Ley 23 de 1991 contiene un capítulo especial sobre el particular, denominado "La conciliación contenciosa administrativa". En este se establece este mecanismo alternativo como una posibilidad, antes de iniciar el litigio o una vez se hubiese iniciado.

En 1998 se expidió la Ley 446, la cual desarrolla un acápite en materia de conciliación contenciosa administrativa en el que determina los asuntos susceptibles de conciliación, las sanciones por inasistencia a la audiencia y los comités de conciliación.

Por medio del Decreto 2511 de 1998, el Gobierno nacional de Colombia recalcó que podrían ser conciliables los asuntos particulares y económicos objeto de las acciones de nulidad y restablecimiento del derecho, reparación directa y controversias contractuales, así como estableció el procedimiento para adelantar el trámite conciliatorio.

En el 2000 se expidió el Decreto 1214, por el cual se establece la integración y las funciones de los comités de conciliación de las entidades estatales, creados por la Ley 446 de 1998. De igual forma, se prohíbe la celebración de audiencias de conciliación en materia contenciosa administrativa en centros de conciliación, hasta tanto se reglamente el funcionamiento de estos centros.

Con el Decreto 1908 de 2000 se expidió el reglamento para categorizar los centros de conciliación en Colombia, estableciendo requisitos especiales para los conciliadores en materia contenciosa administrativa."

Posteriormente, el "Capítulo V" de la Ley 640 de 2001 estableció que la conciliación extrajudicial en Colombia podría ser adelantada por los centros de conciliación autorizados y por el Ministerio Público. Poco después, la Corte Constitucional, en la Sentencia C-893 de 2001, declaró inexequible la competencia de los centros de conciliación en esta materia, de modo que quedó la competencia exclusiva en cabeza de los agentes del Ministerio Público para conocer las conciliaciones extrajudiciales en materia contenciosa administrativa.

En el 2009 se presenta un cambio abrupto en cuanto a la conciliación contenciosa administrativa. Se impone, de manera arbitraria y obligatoria, el adelantamiento de la conciliación como requisito para abrir las puertas de la jurisdicción. Efectivamente, la Ley 1285, de forma mimetizada, adicionó el artículo 42A a la Ley 270 de 1996 estatutaria de la administración de justicia en Colombia. Esto convirtió lo que hasta ese momento era una opción en un requisito sine qua non para ejercer las acciones consagradas en los artículos 85, 86 y 87 del Decreto 01 de 1984, por el cual se reforma el Código Contencioso Administrativo.

De forma casi inmediata, cuatro meses después el Gobierno de Colombia expide el Decreto 1716 de mayo de 2009. En este aclara qué temas quedaban por fuera de la conciliación prejudicial obligatoria, cómo sería el trámite y establece funciones precisas para los comités de conciliación de las entidades públicas que, ahora sí, realizarían un trabajo permanente y no esporádico (como lo venían haciendo).

Con la expedición de la Ley 1395 de 2010 se trae al contexto administrativo un segundo tipo de conciliación obligatoria como requisito para que la entidad estatal condenada en primera instancia pueda acceder a la segunda instancia judicial.

Esta audiencia de conciliación la concibió el legislador como una medida de descongestión judicial que les permitiría a los tribunales contenciosos administrativos del país descongestionarse, pues de llegar a un acuerdo conciliatorio respecto al fallo condenatorio se evitaría que llegara el expediente al superior jerárquico en apelación.

Era tal la congestión en la jurisdicción contenciosa administrativa en Colombia que esta nueva forma de conciliación obligatoria traía un sinfín de esperanzas para los operadores judiciales. Se pregonaba, por ejemplo, lo siguiente:

en la práctica esta audiencia resultaría muy útil, tratándose de condenas impuestas en temas respecto de los cuales existen suficientes precedentes jurisprudenciales de las altas cortes, verbigracia, las demandas contra Cajanal, por reliquidación de la pensión 
gracia, o inclusión de nuevos factores salariales o contra la caja de retiros de las Fuerzas Militares por el reconocimiento de la prima de actualización, etcétera; máxime cuando la propia Ley 1395 del 2010 en el artículo 114, le impone a las entidades públicas de cualquier orden el tener en cuenta los precedentes jurisprudenciales en materia contencioso administrativa, siempre que por los mismos hechos y pretensiones se hubieren proferido cinco o más casos análogos (Toscano y Ortiz, 2012, p. 17).

Resulta importante señalar que el carácter obligatorio de la audiencia de conciliación, con respecto a la asistencia del apoderado que presenta recurso de apelación a esta como requisito para la concesión del recurso de apelación, se convierte en un instrumento de cohesión para las entidades públicas que resultan condenadas en primera instancia, a fin de que reevalúen la posibilidad de conciliar o no dicha sentencia, en pro de salvaguardar el erario público y de contribuir con la descongestión judicial.

Posteriormente, se expide en Colombia un nuevo Código Administrativo y de la Contencioso Administrativo (CPACA), por medio de la Ley 1437 de 2011. De esta manera, se mantiene la conciliación como requisito para la admisión del recurso de apelación presentado en contra de la sentencia desfavorable a los intereses del Estado, y se intenta así que muchos procesos obtuvieran una resolución en primera instancia, lo cual contribuyó a la descongestión de la jurisdicción contenciosa administrativa (Ballen, 2006, p. 1).

Con relación a las etapas del nuevo procedimiento contencioso administrativo tenemos: 1) la primera que va desde la presentación de la demanda hasta la audiencia inicial; 2) desde la finalización de la anterior hasta la culminación de la audiencia de pruebas; y 3) desde la terminación de la anterior, comprende la audiencia de alegaciones y juzgamiento y culmina con la notificación de la sentencia.

Así las cosas, en la actualidad existen tres posibilidades de solucionar directamente las controversias contenciosas administrativas acudiendo a la conciliación. La primera de ellas, previa y obligatoria, denominada "conciliación prejudicial", consagrada en el numeral $1^{\circ}$ del artículo 161 del CPACA, la cual se adelanta ante la Procuraduría
General de la Nación como representante en Colombia de los intereses de la sociedad, de conformidad con lo establecido en el artículo 118 de la Constitución.

Una vez se entabla el litigio existen dos posibilidades formales, en el marco del procedimiento contencioso administrativo, para hacer uso de la conciliación judicial como mecanismo alternativo de solución de conflictos. La primera se encuentra establecida en el desarrollo de la audiencia inicial, prevista en el numeral $8^{\circ}$ del artículo 180 , el cual estipula lo siguiente: "En cualquier fase de la audiencia el juez podrá invitar a las partes a conciliar sus diferencias, caso en el cual deberá proponer fórmulas de arreglo, sin que ello signifique prejuzgamiento". Asimismo, la segunda posibilidad, prevista en el inciso $4^{\circ}$ del artículo 192 del CPACA, que estipula:

cuando el fallo de primera instancia sea de carácter condenatorio y contra el mismo se interponga el recurso de apelación, el Juez o Magistrado deberá citar a audiencia de conciliación, que deberá celebrarse antes de resolver sobre la concesión del recurso. La asistencia a esta audiencia será obligatoria. Si el apelante no asiste a la audiencia, se declarará desierto el recurso.

Una vez se profiere sentencia condenatoria en contra de la entidad estatal y se presenta recurso de apelación, se convoca audiencia de conciliación como requisito de admisibilidad para la consecución del recurso de apelación.

Debido a esto, se considera esta ley como una de las fundamentales a nivel de asuntos de conciliación, pues, en específico, recopila y plantea de forma clara dicho mecanismo alternativo de solución de conflictos, no solo antes sino durante y después del litigio.

\section{Análisis doctrinal de la conciliación}

Tal y como lo ha definido Vargas (2000, p. 36), la conciliación es el "acto jurídico e instrumento por medio del cual las partes en conflicto, antes de un proceso o en el transcurso de este, se someten a un trámite conciliatorio para llegar a un convenio de todo aquel susceptible de transacción”. Es decir, este autor destaca la conciliación como un 
mecanismo idóneo por medio del cual las partes de una controversia susceptible de ser conciliada o tranzada, con la intervención de un tercero neutral y capacitado, denominado "conciliador" o "juez" (dependiendo del caso), pueden de forma pacífica, ágil, directa, oportuna y, ante todo, justa, llegar a un arreglo directo entre las partes, de modo que se evitan seguir con el conflicto en una instancia judicial. De esta manera, por medio de un tercero neutral y capacitado, afirma el autor, se puede llegar a fórmulas de arreglo justas para las partes en conflicto con el respeto a sus derechos constituidos. Lo anterior, si se tiene en cuenta que dicho mecanismo de solución de conflictos hace tránsito a cosa juzgada, y que lo decidido por las partes en audiencia de conciliación debe ser cumplido a cabalidad para el buen desarrollo de dicho mecanismo.

De igual forma, se hace importante destacar la conciliación extrajudicial, la cual, según doctrinantes como Cristancho Moyano (2002), ha centrado su particular interés en lo relacionado con la conciliación extrajudicial. En este sentido, la define como aquella "que se realiza antes de un proceso y/o por fuera de la Litis judicial” (2002). Cristancho Moyano caracteriza lo que es la conciliación extrajudicial, en el entendido de que es aquella que se realiza sin haber iniciado un proceso en una instancia judicial, o, habiéndose iniciado un proceso, las partes, de mutuo acuerdo y con el mismo objetivo de darle fin a la controversia que presentan, deciden acudir ante un tercero neutral y calificado denominado "conciliador", a fin de que los oriente, guie y, finalmente, los dirija al logro de una conciliación de forma directa. El autor destaca en este caso la importancia de llevar a cabo una conciliación fuera de una instancia judicial, pues esta resulta ser más beneficiosa y justa para las partes en cuestión, ya que en este caso ambos extremos buscarán la mejor solución ante el problema que presentan. Lo anterior, si se tiene en cuenta que también existe la conciliación judicial o procesal, la cual se desarrolla en el marco de un proceso judicial y bajo la dirección de una persona autorizada, denominada “juez”, quien buscará —al igual que en la conciliación extrajudicial- lograr un acuerdo entre las partes.
Ahora bien, el doctrinante Romero ha enfatizado que "el conciliador debe determinar el centro del conflicto, para lo cual debe definir los extremos del conflicto" (2006, p. 28). Romero es enfático en afirmar que es el conciliador quien dirige y orienta, así como el principal encargado de que al final de la audiencia de conciliación las partes puedan llegar a un acuerdo; es el conciliador quien debe realizar el acercamiento a las partes de forma directa, con el objetivo de obtener información del conflicto en cuestión, y así proponer a estas fórmulas de arreglo en beneficio de todas. Para esto debe tener en cuenta, principalmente, que la conciliación como mecanismo alternativo de solución de conflictos brinda a los intervinientes la resolución del conflicto de manera pronta, eficaz y con la participación directa de los afectados en el conflicto, pues son estos los que por medio del conciliador resolverán el conflicto en cuestión.

En materia de la conciliación contenciosa administrativa encontramos el libro de González Rey (2011), publicado por la Universidad Externado de Colombia. En ese se presenta un buen recuento de la normatividad expedida hasta esa fecha sobre este tipo de conciliación, de manera que proporciona un referente legislativo sobre el tema.

Por último, Peláez Gutiérrez (2016), en su trabajo de investigación (el cual luego se publica como libro), realiza una buena presentación del tema de la conciliación en Colombia. Aterriza en el desarrollo que ha tenido en el campo contencioso administrativo, especialmente en lo relativo a los requisitos para su ejercicio y su homologación judicial posterior.

\section{B. Resultados}

En este apartado se presentan los resultados más relevantes de la investigación realizada por el semillero Ratio Iuris, adscrito al Grupo de Conciencia de la Universidad Surcolombiana. Esta trata la pertinencia como medida de descongestión judicial de la audiencia de conciliación convocada como requisito de admisión del recurso de apelación interpuesto contra las sentencias condenatorias, en la jurisdicción contenciosa administrativa en el Huila, en el periodo 2011-2015. La investigación 
abordó una metodología cuantitativa descriptiva, la cual comprendió el registro, la cuantificación, la descripción, el análisis y la interpretación de los hallazgos encontrados en los procesos objeto de investigación. Debido a la enorme cantidad de procesos hallados (un total de 1023), la investigación abordó una muestra del $10 \%$, es decir, 102 audiencias de conciliación en procesos de controversias contractuales, reparación directa, de nulidad y restablecimiento del derecho. A continuación, se presentan los hallazgos.

Figura 1. Trámite del recurso de apelación. Fuente: elaboración propia con base en los 102 procesos en los que se interpuso apelación

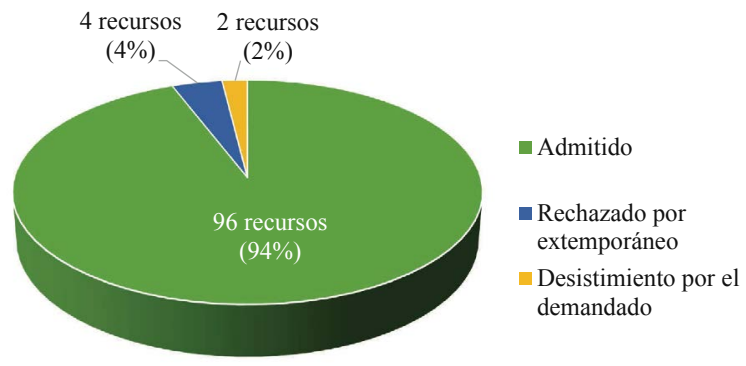

En la Figura 1 se observa que, de los 102 recursos de apelación interpuestos por las entidades públicas demandadas en contra de las sentencias condenatorias y dictadas en el periodo 2011--2015 en la jurisdicción contenciosa administrativa del Huila, solo 96 de ellos, equivalentes al $94 \%$, fueron admitidos. En cambio, cuatro de estos recursos, es decir el $4 \%$, fueron interpuestos por fuera del término legal, de manera que fueron rechazados por el juez de conocimiento. Finalmente, en dos casos la entidad apelante desistió del recurso. Lo anterior demuestra que la gran mayoría de los recursos de apelación interpuestos por las entidades públicas demandadas son admitidos por el juez, pues se presentan de forma oportuna y con los fundamentos necesarios para su estimación y admisión. De igual forma, dicha admisión del recurso brinda la posibilidad a la entidad pública de que el superior jerárquico del juez que dictó sentencia condenatoria pueda reconsiderar su sentencia, siempre y cuando el recurso sea sustentando de manera eficaz, lo que, finalmente, puede conllevar a que en dicha instancia judicial la sentencia sea a favor de la entidad pública, o que, en su defecto, la sentencia condenatoria pueda ser menor, de manera que se evite un detrimento patrimonial. Por otra parte, cabe resaltar que un $4 \%$ de los recursos interpuestos se presentan de forma extemporánea, y por esta razón son rechazados. Esto es preocupante en la medida en que las entidades públicas no ejercen los mecanismos necesarios para evitar una condena, sino que, por el contrario, toman dicho recurso como algo sin relevancia y no le dan la importancia necesaria para su presentación. Por último, es necesario señalar que solo interponer el recurso no es suficiente, pues la entidad pública debe sustentarlo y estar presente en toda su etapa hasta que sea debidamente resuelto. Esto, debido a que, en algunas ocasiones, la entidad pública desiste de dicho recurso y con esto desiste de la posibilidad de que la sentencia sea favorable. Así evita un detrimento patrimonial, pues dichos dineros que se pagan en condenas pueden ser eficaces y necesarios para solventar otras problemáticas sociales, como lo son, por ejemplo, la educación, la salud y demás garantías que debe brindar el Estado a fin de garantizar una vida digna a cada asociado.

Figura 2. Asistencia del apelante a la audiencia de conciliación. Fuente: elaboración propia con base en los 96 recursos interpuestos por parte de las entidades públicas demandadas

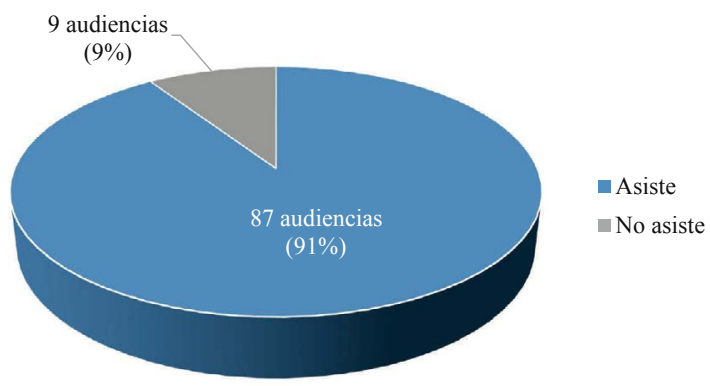

En la Figura 2 se evidencia que, de los 96 recursos de apelación interpuestos por las entidades públicas demandadas en contra de las sentencias condenatorias dictadas en el periodo 2011-2015 en la jurisdicción contenciosa administrativa del Huila y que fueron admitidos, por lo cual se convocó a audiencia de conciliación, en un total de 
87 (91\%) de dichas audiencias la entidad apelante asistió, pero en nueve ( $9 \%)$ no compareció, lo cual llevó a que el juez de conocimiento declarara desierto el recurso de apelación. Esto demuestra cómo, a pesar de que en la mayoría de las audiencias de conciliación convocadas la entidad pública asiste, existe un porcentaje relevante en las que dicha entidad no asiste, y el recurso es declarado desierto. Esta inasistencia conlleva a que la entidad pública deseche su única y última instancia judicial para lograr una sentencia favorable y pueda evitar de esta manera una condena. Al no asistir a dicha diligencia y tratar de buscar una conciliación en la que su condena sea menor, se comportan de manera irresponsable con los recursos del Estado. Es por esto que dichas entidades públicas que desisten del recurso por su inoperancia deben responder ante el Estado, pues de forma autónoma e insensata suprimen la posibilidad de evitar una condena o lograr una conciliación que disminuya de forma considerable su condena

Figura 3. Concepto de comité de conciliación. Fuente: elaboración propia con base en las 87 audiencias de conciliación convocadas

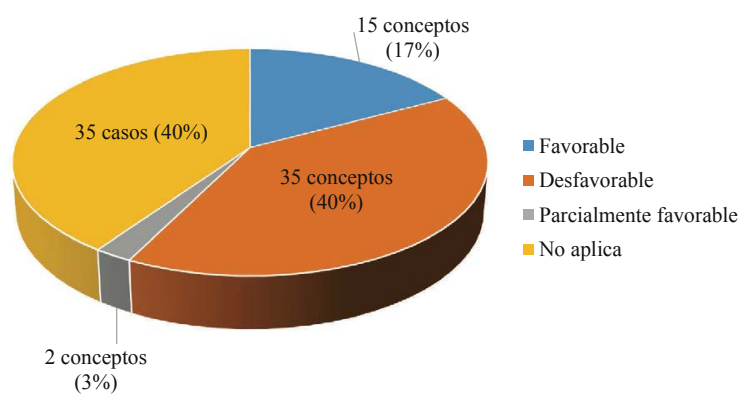

En la Figura 3 se puede evidenciar cómo en el desarrollo de las 87 audiencias de conciliación convocadas por los recursos de apelación admitidos contra las sentencias condenatorias, dictadas en el periodo 2011-2015 en la jurisdicción contenciosa administrativa del Huila, en las que asistió la entidad apelante, está presentó 15 conceptos del Comité de Conciliación favorables, es decir, un $17 \%$. Por otra parte, 35 conceptos desfavorables (40\%), además de dos conceptos parcialmente favorables (3\%), y en 35 casos (40\%), la entidad apelante no presentó concepto de dicho comité, ya que este no se exigía en dicha entidad. Lo anterior evidencia que el Comité de Conciliación en las audiencias de conciliación no rinde conceptos, y cuando lo hace es de forma desfavorable (en su mayoría), lo cual agudiza de forma considerable la posibilidad de lograr una conciliación entre las partes intervinientes. Esto en razón a que dicho ente es el que fija las "directrices institucionales para la aplicación de los mecanismos de arreglo directo, tales como la transacción y la conciliación, sin perjuicio de su estudio y decisión en cada caso concreto". Es decir, dicho comité debería estar obligado a fijar, formular y ejecutar políticas que garanticen una conciliación entre las partes, o que por lo menos a que las partes participen activamente en la audiencia. De lo contrario, el Comité de Conciliación sería un ente sin ningún objetivo $\mathrm{y}$, por ende, sin importancia en una audiencia de conciliación. Ahora, si se tienen presente la poca eficacia de los comités de conciliación podría pensarse en suprimir su intervención en dicha diligencia e incentivar otras opciones que sean más efectivas a fin de lograr un acuerdo entre las partes.

Figura 4. Acuerdo conciliatorio. Fuente: elaboración propia con base en las 87 audiencias de conciliación realizadas

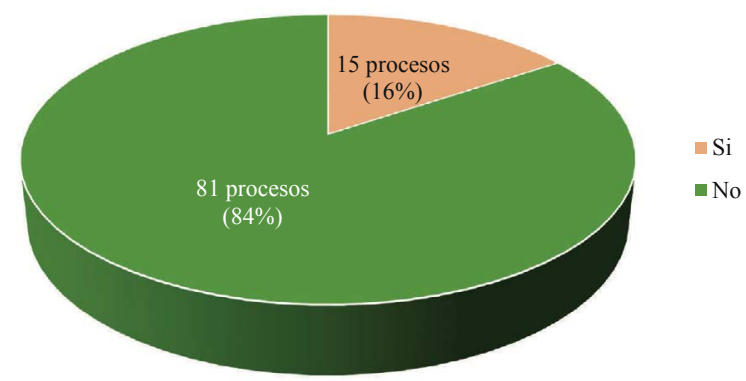

De la Figura 4 se puede inferir que, de las 87 audiencias de conciliación convocadas por los recursos de apelación admitidos contra las sentencias condenatorias dictadas en el periodo 2011-2015 en la jurisdicción contenciosa administrativa del Huila, en las que asistió la entidad apelante, en 15 hubo acuerdo conciliatorio, es decir, en un $16 \%$. En contraposición, en las 81 audiencias restantes 
no hubo acuerdo conciliatorio, lo cual demuestra que efectivamente la audiencia de conciliación no ha sido un mecanismo de descongestión judicial efectivo, pues en los procesos revisados se evidenció que las partes intervinientes no llegan a un acuerdo conciliatorio, sino que, por el contrario, asisten a esta diligencia sin animo conciliatorio y sin ninguna expectativa de conciliar; en cambio, toman esta diligencia como una etapa procesal, un requisito más que se debe agotar.

Figura 5. Cuantía de la sentencia objeto del acuerdo de conciliación. Fuente: elaboración propia con base en las 15 sentencias en las que hubo acuerdo conciliatorio

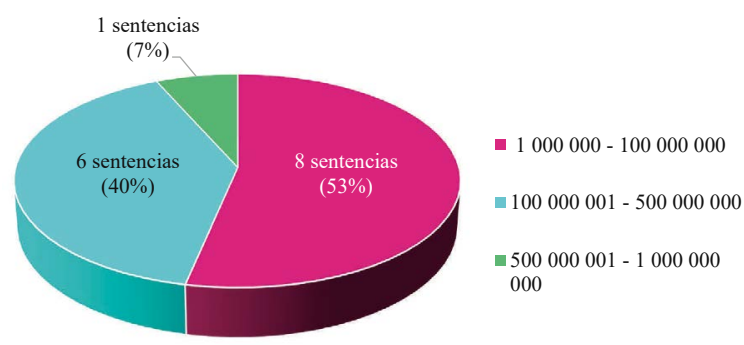

En la Figura 5 se describen los rangos de los montos de las condenadas a pagar por parte de las entidades pública y se tienen en cuenta las 15 sentencias que fueron objeto de un acuerdo conciliatorio. En dichas audiencias de conciliación se puede determinar que el monto de condena en ocho de ellas oscilaba entre COP 1000000 y cop 100000 000. Asimismo, seis de estas condenas entre los COP 100000001 y COP 500000 000; y en un fallo, la condena se encontraba entre cop 500000001 y cOP 1000000000 . Esto evidencia que los fallos condenatorios de las entidades públicas son significativamente altos. Es decir, dichas condenas desembocan en un gran detrimento patrimonial a causa de los deficientes servicios brindados por parte de las entidades públicas que terminan en demandas. Es por esto que es deber del Estado controlar y castigar todas aquellas actuaciones realizadas por las entidades públicas, pues estas deben estar ajustadas a derecho y, por ende, evitar demandas que terminen en cuantiosas condenas.
Figura 6. Análisis económico del acuerdo conciliatorio. Fuente: elaboración propia con base en los 15 procesos en los que hubo acuerdo conciliatorio

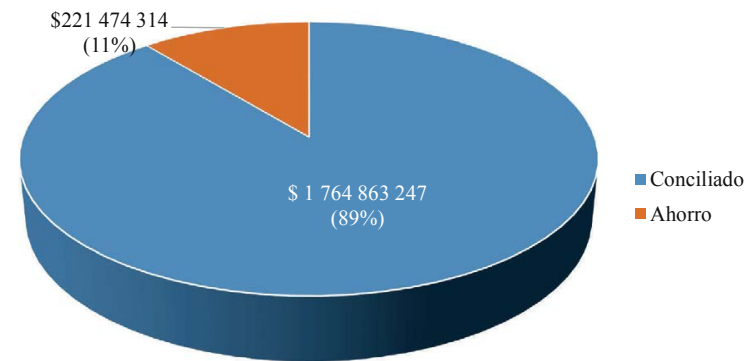

En la Figura 6 se analizó el beneficio económico obtenido en el marco de los 15 procesos en los que hubo acuerdo conciliatorio. Asimismo, se evidencia un ahorro total del $11 \%$, es decir, una suma de cop 221474314 con respecto al valor total de la condena. Esto demuestra que, gracias al acuerdo conciliatorio en la audiencia de conciliación realizada, el valor final de la condena en estos procesos disminuyó considerablemente. Además, demuestra que dicho mecanismo de solución de conflicto es efectivo y verdaderamente evita que la entidad pública condenada tenga que cancelar sentencias cuantiosas, pues queda demostrado que cuando existe acuerdo conciliatorio la condena a pagar por parte de la entidad es menor. De esta manera, se evita que el proceso continúe dentro de la jurisdicción, se descongestionan así los despachos judiciales y se logra el objetivo para el cual fue creada dicha diligencia: la descongestión judicial.

\section{Conclusión}

La audiencia de conciliación obligatoria, de la que tratan los artículos 70 de la Ley 1395 de 2010 y el inciso $4^{\circ}$ del artículo 192 de la Ley 1437 de 2011, en la jurisdicción contenciosa administrativa del Huila, en el periodo 2011- 2015, fue pertinente como medida de descongestión judicial toda vez que se lograron acuerdos conciliatorios en un $16 \%$ de las sentencias condenatorias estudiadas.

Además, dichos acuerdos conciliatorios generaron beneficios jurídicos y económicos para las entidades demandadas, ya que los montos de las condenas se redujeron en un $11 \%$, lo que fijó un 
ahorro para el erario público de cop 221474314 . Así, se logró una descongestión judicial, ya que dichos acuerdos conciliatorios desencadenaron la terminación del proceso y, en consecuencia, la no resolución de fondo del recurso de apelación por parte del Tribunal Administrativo del Huila.

Asimismo, se concluye que las entidades públicas que cuentan con Comité de Conciliación son más susceptibles a conciliar que aquellas que no lo ostentan, ya que de las 15 sentencias condenatorias conciliadas, todas tenían un concepto favorable de dicho comité. Lo anterior demuestra que estos comités se convierten en instancias decisivas para afrontar la audiencia de conciliación.

Finalmente, se evidenció la falta de diligencia de los apoderados judiciales de las entidades públicas demandadas, ya que, en cuatro oportunidades, el recurso de apelación fue interpuesto por fuera del término, y en otras nueve ocasiones dicho abogado con su poderdante no compareció a la audiencia de conciliación. Esto desencadenó que se declarara desierto el recurso de apelación, lo que generó que dicha condena no fuera objeto de un acuerdo conciliatorio y el Estado tuviera que desembolsar recursos públicos sin la oportunidad de la revisión de un juez superior.

\section{Recomendaciones}

Conforme al análisis normativo y doctrinal, así como a los resultados de la investigación, se propone que el juez contencioso que debería celebrar la audiencia de conciliación obligatoria de la que tratan los artículos 70 de la Ley 1395 de 2010 y el inciso $4^{\circ}$ del artículo 192 de la Ley 1437 de 2011, es el de segunda instancia, ya que es un tercero imparcial, y no el juez de primera instancia, quien ya tiene un concepto previo que lo llevó a la certeza de condenar a la entidad estatal.

Se hace necesario una mayor capacitación de los miembros de los comités de conciliación de las entidades públicas, con el propósito de que tengan una participación proactiva al momento de analizar las condenas impuestas a la entidad y planteen fórmulas de arreglo que protejan los recursos estatales, los cuales, en últimas, son los recursos de todos.
En aquellos casos que por descuido del representante legal de la entidad o su apoderado los recursos de apelación se declaren desiertos por falta de sustentación del recurso o inasistencia a la audiencia de conciliación, deben iniciarse los respectivos procesos disciplinarios y fiscales que permitan recuperar los dineros perdidos.

Por último, se recomienda que el juez contencioso que celebre la audiencia de conciliación obligatoria de la que tratan los artículos 70 de la Ley 1395 de 2010 y el inciso $4^{\circ}$ del artículo 192 de la Ley 1437 de 2011 muestre una actitud más proactiva, de manera que formule propuestas de arreglo y no se supedite a una actividad mecánica basada únicamente en el concepto que ha emitido el Comité de Conciliación de la entidad condenada.

\section{Referencias}

Ballén Molina, R. (2006). Causas de la congestión en la jurisdicción contenciosa administrativa. Revista Prolegómenos Derechos y Valores, 9(18), 33-57.

Constitución Política de Colombia (1991). [Const]. (Colombia).

Cristancho Moyano, J. (2002) La conciliación y mecanismo alternativo de solución de conflictos. Bogotá: Ediciones Librería del Profesional.

Decreto 2158. (1948). Sobre Procedimientos en los juicios del Trabajo. Diario Oficial 26773, 21 de julio de 1948.

Decreto 1818. (1998), Por medio del cual se expide el Estatuto de los mecanismos alternativos de solución de conflictos”. Diario Oficial 43380, 7 de septiembre.

Decreto 2511. (1998). Por el cual se reglamenta la conciliación extrajudicial contencioso administrativa y en materia laboral previstas en la Parte III, Título I, capítulos 1, 2 y 3, Secciones 1, 2 y 3 de la Ley 446 de 1998, y en los artículos 19, 21 y 22 del Código Procesal del Trabajo”. Diario Oficial 43451, 15 de diciembre de 1998.

Decreto 1214. (2000). Por el cual se establecen funciones para los Comités de Conciliación de que trata el artículo 75 de la Ley 446 de 1998 y se dictan otras disposiciones. Diario Oficial 44069, 5 de julio de 2000.

Decreto 1908. (2000). Por el cual se expide el reglamento para categorizar los centros de conciliación. Diario Oficial 44178, 29 de septiembre de 2000.

Decreto 1716. (2009). Por el cual se reglamenta el artículo13 de la Ley 1285 de 2009, el artículo 75 de la Ley 446 
de 1998 y del Capítulo v de la Ley 640 de 2001. Diario Oficial 47349, 14 de mayo 1de 2009.

Decreto Constitucional 2651. (1991). Por el cual se expiden normas transitorias para descongestionar los despachos judiciales. Diario Oficial 40177, 25 de noviembre de 1991.

Decreto Ley 1818. (1998). [Congreso de la República de Colombia]. Por medio del cual se expide el Estatuto de los mecanismos alternativos de solución de conflictos. Diario Oficial 43380, 7 de septiembre de 1998.

González Rey, S. (2010). Conciliación extrajudicial en asuntos contencioso administrativos: hacia un nuevo paradigma. Revista Digital de Derecho Administrativo, 4.

- - - . (2011). Conciliación extrajudicial en asuntos contencioso administrativos. Bogotá: Universidad Externado de Colombia.

Ley 120 de 1920. Sobre conciliación y arbitraje en los conflictos colectivos del trabajo, que adiciona la Ley 78 de 1919, sobre huelgas. Diario Oficial 17352, 7 de octubre de 1920.

Ley 23. (1991). [Congreso de la República de Colombia]. Por medio de la cual se crean mecanismos para descongestionar los Despachos Judiciales, y se dictan otras disposiciones. Diario Oficial 39.752, 21 de marzo de 1991.

Ley 270. (1996). [Congreso de la República de Colombia]. Estatutaria de la Administración de Justicia. Diario Oficial 42745, 15 de marzo de 1996.

Ley 446. (1998). [Congreso de la República de Colombia]. Por la cual se adoptan como legislación permanente algunas normas del Decreto 2651 de 1991, se modifican algunas del Código de Procedimiento Civil, se derogan otras de la Ley 23 de 1991 y del Decreto 2279 de 1989, se modifican y expiden normas del Código Contencioso Administrativo y se dictan otras disposiciones sobre descongestión, eficiencia y acceso a la justicia. Diario Oficial 43.335, 8 de julio de 1998.
Ley 640. (2001). [Congreso de la República de Colombia]. Por la cual se modifican normas relativas a la conciliación y se dictan otras disposiciones. Diario Oficial 44303, 24 de enero de 2001.

Ley 1285. (2009). [Congreso de la República de Colombia]. Por medio de la cual se reforma la Ley 270 de 1996 Estatutaria de la Administración de Justicia. Diario Oficial 47240, 22 de enero de 2009.

Ley 1395. (2010). [Congreso de la República de Colombia]. Por la cual se adoptan medidas en materia de descongestión judicial. Diario Oficial 47768, 12 de julio de 2010.

Ley 1437. (2011). [Congreso de la República de Colombia]. Por la cual se expide el Código de Procedimiento Administrativo y de lo Contencioso Administrativo. Diario Oficial 47956, 18 de enero de 2011.

Osorio, A. (2002). Conciliación mecanismo alternativo de solución de conflictos por excelencia (tesis de grado). Facultad de Ciencias Jurídicas, Universidad Javeriana, Bogotá, Colombia. Recuperado de http://www.javeriana.edu.co/biblos/tesis/derecho/dere4/Tesis-15.pdf

Palacio Hincapié, J. (2006). La conciliación en materia contenciosa administrativa. Bogotá: Librería Ediciones del Profesional.

Peláez Gutiérrez, V. (2016). La conciliación en el derecho administrativo colombiano. Bogotá: Universidad Externado de Colombia.

Romero, H. (2006). La conciliación judicial y extrajudicial. Su aplicación en derecho colombiano. Bogotá: Editorial Legis.

Toscano López, B. (2001). La eficacia de la audiencia del artículo 70 de la ley 1395 de 2010. Bogotá. Recuperado de http://repository.unimilitar.edu.co/bitstream/10654/9235/2/ToscanoLopezBrunoEdwin2012. pdf

Vargas, H. (2009). Marco para la implementación de la conciliación en equidad. Bogotá: Ministerio del Interior y de Justicia, Imprenta Nacional. 